\title{
Fluxos de Investimentos Estrangeiros Diretos e Cooperação Sul-Sul: o desenvolvimento econômico brasileiro e sua influência nos demais países da américa latina [1990 - 2018]
}

Foreign Direct Investment Flows and South-South Cooperation: Brazilian

Economic Development and Its Influence in Other Latin American Countries

[1990 - 2018]

Flujos de inversión extranjera directa y cooperación Sur-Sur: desarrollo

económico brasileño y su influencia en otros países latinoamericanos [1990 -

2018]

Flux d'investissements directs étrangers et coopération Sud-Sud: développement économique du Brésil et son influence dans d'autres pays d'Amérique latine

[1990 - 2018]

\section{Maria Clara Leadebal Celestino}

\section{OpenEdition}

Journals

\section{Edição electrónica}

URL: http://journals.openedition.org/espacoeconomia/9926

DOI: 10.4000/espacoeconomia.9926

ISSN: 2317-7837

\section{Editora}

Núcleo de Pesquisa Espaço \& Economia

\section{Refêrencia eletrónica}

Maria Clara Leadebal Celestino, « Fluxos de Investimentos Estrangeiros Diretos e Cooperação Sul-Sul: o desenvolvimento econômico brasileiro e sua influência nos demais países da américa latina [1990 2018] », Espaço e Economia [Online], 16 | 2019, posto online no dia 03 janeiro 2020, consultado o 10 janeiro 2020. URL : http://journals.openedition.org/espacoeconomia/9926 ; DOI : 10.4000/ espacoeconomia.9926

Este documento foi criado de forma automática no dia 10 janeiro 2020.

(C) NUPEE 


\section{Fluxos de Investimentos}

\section{Estrangeiros Diretos e Cooperação} Sul-Sul: o desenvolvimento econômico brasileiro e sua influência nos demais países da
américa latina [1990 - 2018]

Foreign Direct Investment Flows and South-South Cooperation: Brazilian Economic Development and Its Influence in Other Latin American Countries [1990 - 2018]

Flujos de inversión extranjera directa y cooperación Sur-Sur: desarrollo económico brasileño y su influencia en otros países latinoamericanos [1990 2018]

Flux d'investissements directs étrangers et coopération Sud-Sud: développement économique du Brésil et son influence dans d'autres pays d'Amérique latine [1990 - 2018]

Maria Clara Leadebal Celestino

\section{Introdução.}

1 Vive-se em um contexto onde a geopolítica e a geoeconomia se entrelaçam, estabelecendo-se os investimentos estrangeiros diretos como estratégia dos países e empresas multinacionais. Segundo Amal e Seabra (2007), os Investimentos Estrangeiros Diretos são movimentos de capital no sentido de investimentos em empresas com interesses de controles acionários duradouros e explorações em outros países com o objetivo de influir na gestão da mesma. Nesse contexto, os principais tipos de projetos 
são os de busca de novos mercados - atendimento de mercado interno do país receptor -, de produtos eficientes - menor custo de produção -, de recursos - acesso a matérias primas e mão de obra com custos relativamente baixos -, e de ativos - obtenção de ativos estratégicos por implantação de novas plantas fabris, fusões, aquisições ou joint ventures.

2 Além das exportações e transferências de recursos contratuais, os investimentos diretos são uma forma de suprir o mercado, podendo ter específicas vantagens no que se refere à localização, internacionalização e obtenção de propriedade. São também uma forma de se buscar o desenvolvimento econômico, seja do país investidor, país receptor, ou da empresa. Teotônio dos Santos (2015, p.3) já definia o próprio desenvolvimento como:

adoção de normas de comportamento, atitudes e valores identificados com a racionalidade econômica moderna, caracterizada pela busca da produtividade máxima, a geração de poupança e a criação de investimentos que levassem à acumulação permanente da riqueza dos indivíduos e, em consequência, de cada sociedade nacional.

3 Nesse contexto, a acumulação de riqueza das empresas através desses investimentos, por exemplo, levaria à riqueza da sociedade nacional. No entanto, é preciso colocar que nem sempre essa riqueza é distribuída socialmente, havendo mais um crescimento econômico particular que um desenvolvimento social propriamente dito.

4 Assim, é importante colocar que segundo a Organização para Cooperação e Desenvolvimento Econômico (OCDE) entre 1990 e 2006, o Brasil foi um dos "países em desenvolvimento" que mais fizeram fusões e aquisições dentre os países desta organização (SPOSITO, SANTOS, 2012). Neste sentido, parte-se de um contexto de mundialização das empresas por meio do comércio externo para investimentos muito mais complexos, que vem permitindo o aumento de poder das empresas multinacionais em distintos territórios nacionais. Dessa forma, esses investimentos ampliam a participação brasileira no mercado internacional e consolida sua projeção hegemônica nas relações de cooperação do Sul global.

5 Entende-se por Cooperação Sul-Sul o processo de associação onde se respeitam as particularidades dos associados e se estabelecem consensos, sem que haja interferência nos assuntos uns dos outros e destacando o respeito pelos desenvolvimentos locais, é possível pensar esta prática de uma forma menos hierárquica (MORASSO; 2013). É preciso considerar então que em termos de Cooperação Econômica, apesar de enfoque específico, os parâmetros são os mesmos.

O presente texto tem o objetivo de entender os Investimentos Estrangeiros Diretos enquanto estratégias de projeção hegemônica regional do Brasil. Para exposição deste trabalho subdividiremos em duas partes, a saber: [a]Fluxos de Investimento e Capitalismo Financeiro - uma discussão conceitual dos Investimentos Estrangeiros Diretos e seus respectivos fluxos no contexto do Capitalismo Financeiro; [b] Resgate Histórico dos Investimentos Externos Diretos: dos anos 90 até 2018 - uma análise histórica comparativa dos dados de IED através de gráficos e mapeamentos no supracitado recorte temporal; e [c] Resultados Econômicos dos IED nos países da América Latina - uma consideração das consequências econômicas destes investimentos, tendo em vista o próprio desenvolvimento regional. 


\section{Fluxos de investimento e capitalismo financeiro}

7 Uma forma de pensar os fluxos de investimento é a apontada por Dunning (1982) que aborda a Teoria Eclética. Esta é uma teoria de produção internacional assim denominada uma vez que se mostra uma das principais linhas de pensamento ao longo dos anos, além de ser relevante para todos os tipos de investimentos estrangeiros diretos, incluindo ainda os três principais veículos da internacionalização de empresas, que são investimentos diretos, exportações e transferências contratuais de recursos. A partir dela, coloca que há predições gerais sobre as possíveis destinações de investimentos. Isto quer dizer que, a medida que uma empresa se depara com vantagens específicas em um determinado país que superam o mercado doméstico, maior é a tendência para a internacionalização.

Outra característica desta teoria é que há três determinantes estruturais: as especificidades dos países, dos tipos de atividades ou indústrias e das empresas ou empreendimentos. Esses determinantes dirão em resumo que a propensão das empresas de um determinado país a se comprometerem com investimentos estrangeiros irá variar de acordo com as características econômicas de seu mercado doméstico do mercado do país em que se interessam em investir, variando também o tipo, proporção e estratégia de projetos e produtos. Neste sentido, muito depende das políticas de governo tanto do país de origem da empresa, quanto do país de destino do investimento da mesma.

9 Já de acordo Chesnais (2001), os investimentos financeiros, enquanto uma forma concentrada do capital, tiram benefícios dos espaços de dominação. Neste sentido, as multinacionais industriais são também responsáveis pelo estabelecimento desta dominação, tanto em sentido político quanto em social. Em associação com investidores institucionais, - no caso brasileiro, os bancos -, é possível então ter ainda mais poder sobre esses parâmetros, com a determinação de ritmo de investimento.

10 Considerando a interdependência desenvolvida pelas IED's, assim como pela presença das multinacionais, é conclusivo o seu caráter coercitivo. Estes investimentos internacionais ressaltam-se mesmo diante dos quantitativos de comércio exterior, devido à sua natureza específica. Esta se dá em razão de suas características de nãoliquidez imediata - já que não se reduz a transações pontuais -, de dimensão intertemporal - uma vez que a decisão de implantação de investimentos origina fluxos de longa periodização -, de implicação de transferência de poder econômico, e de componente estratégico nas decisões de investimento (BOURGUINAT, 1992, apud CHESNAIS, 1996).

11 É neste sentido que a coleta de dados sobre os investimentos estrangeiros diretos se torna vaga e pouco eficaz, o que é evidenciado pela própria definição de IED do FMI de 1977, colocado como um investimento de interesse duradouro em empresa de país distinto do investidor com objetivo de influenciar na gestão desta. Assim, entende-se que o interesse e o controle da gestão dessas empresas devem ser verificados para confirmação de investimento, o que é essencialmente qualitativo e de difícil análise para classificação. Sendo assim, seus dados são na maioria das vezes indicadores de nível e tendência, segundo Chesnais (1996), o que deve ser levado em consideração nos próximos momentos textuais onde os dados serão debatidos.

12 Outro ponto a ser considerado é que a mundialização dessas empresas são de efeitos econômicos, mas também políticos, uma vez que os Estados exercem intervenções e 
influências. Estas intervenções permitiram uma liberdade em plano doméstico e um aumento de possibilidades de investimentos internacionais.

Assim, esses investimentos estrangeiros diretos vêm a ser pensados no contexto da mundialização do capital, que, segundo Chesnais (2001, p.13):

Esta encontra-se ordenada de modo a permitir a apropriação em uma escala "mundial", em condições tão regulares e seguras quanto possível, dos lucros industriais, mas também e, sobretudo, das receitas financeiras, dos juros e dos dividendos. Sua arquitetura tem principalmente por objetivo permitir a valorização em escala internacional de um "capital de investimento financeiro," sobre uma vintena de mercados financeiros desregulados que desenham o espaço da "mundialização financeira".

Esta mundialização é ainda pautada pelos fundamentos da hierarquia política, ainda de acordo com este autor. Isto novamente evidencia que, apesar de o Brasil estar hierarquicamente abaixo dos países centrais, ainda assim, está em condição de semiperiferia exercendo sua hegemonia regional sobre os demais países da América Latina. Sendo assim, essa mundialização não elimina as relações políticas de dominação e dependência entre os países, apenas a reproduz em novas escalas e dinâmicas. Nestes termos, as economias locais geram condições mais voláteis na tentativa de se adaptar às demandas e transformações da mundialização, havendo a precarização do trabalho através da reestruturação de mercado.

Segundo Harvey (2006), a sobrevivência do capitalismo é fundada pela vitalidade das formas de circulação do capital, e, consequentemente, pelas infraestruturas sociais e físicas que sustentam essa circulação. A construção dessas pode partir do princípio de um investimento de Estado, por exemplo, na construção de infraestruturas de energia e de transporte, realizadas pelas multinacionais em questão. Assim, nesse contexto, mais que isso, acabam por se tornar investimentos no próprio capital, contribuindo para sua circulação agora em escala internacional.

\section{Resgate histórico dos Investimentos Externos Diretos: dos anos 90 até 2018}

Remontando aos anos 90, tem-se a retomada das internacionalizações das empresas latinas, uma vez que se tinha um contexto econômico em vias de superação da crise da década anterior. Ainda assim, só se é retomado o protagonismo de investimentos na América Latina ao final dos anos 90, sendo seus investimentos consequência do acirramento competitivo mundial e emergência do oligopólio global.

Neste mesmo período, foi averiguado que os investimentos externos diretos chegaram a superar o intercâmbio comercial, demonstrando a dimensão que esse tipo de investimento adquire para a economia nacional. Desde então, foi averiguado em muitos países periféricos a disputa por IED com direito à adoção de políticas liberalizantes, mesmo que os investimentos fossem voltados principalmente para aquisições, ou seja, desnacionalização, de acordo com Sposito e Santos (2012). Enquanto no centro essas políticas foram uma resposta à crise de acumulação, na periferia, em sua reprodução, foram causa de suas próprias crises de empresas de controle governamental substituídas quase proporcionalmente pelo controle de multinacionais -, além de porta de entrada para a expansão do capital dos países do centro. 
A partir disto, é interessante pensar como historicamente se deram os investimentos feitos pelo (Gráfico 1) e no (Gráfico 2) Brasil, remontando suas associações políticoeconômicas para entender sua evolução.

Gráfico 1 -Fluxo de Investimentos Estrangeiros Diretos do Brasil entre 1990 e 2017 em Milhões de Dólares.

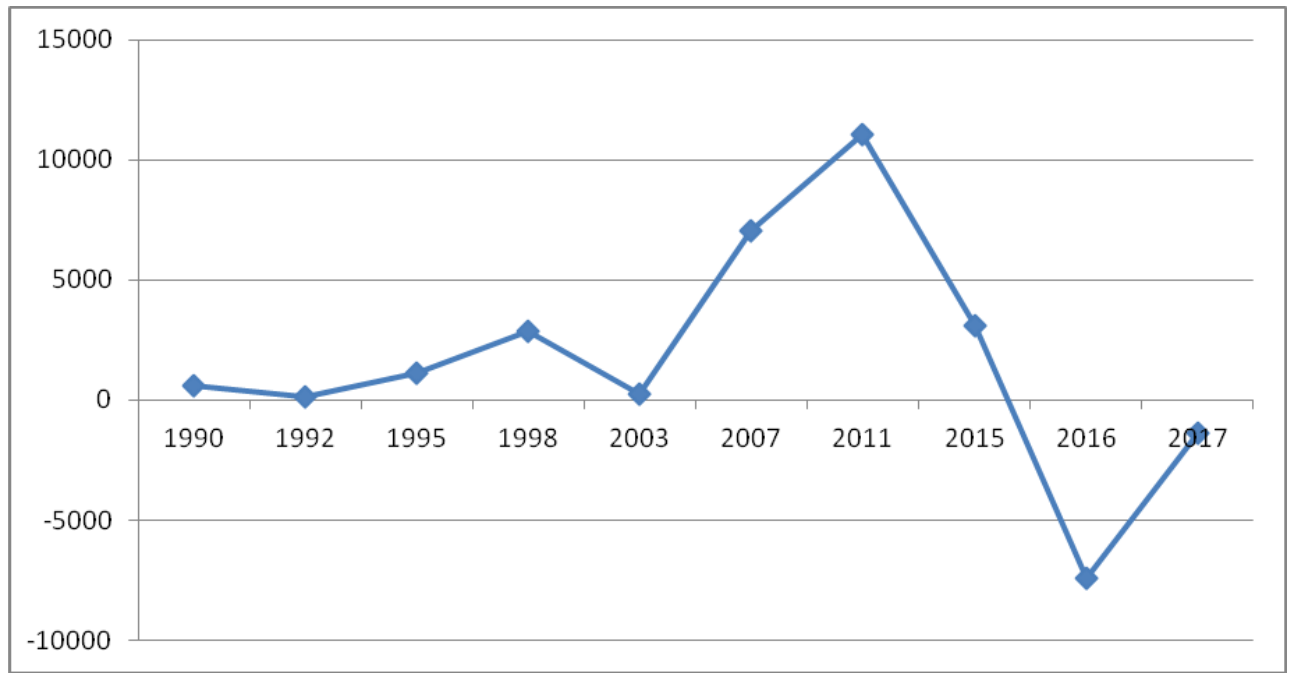

Elaboração: Maria Clara Leadebal Celestino, 2019. Fonte: UNCTAD.

Gráfico 2 - Fluxo de Investimentos Estrangeiros Diretos no Brasil entre 1990 e 2017.

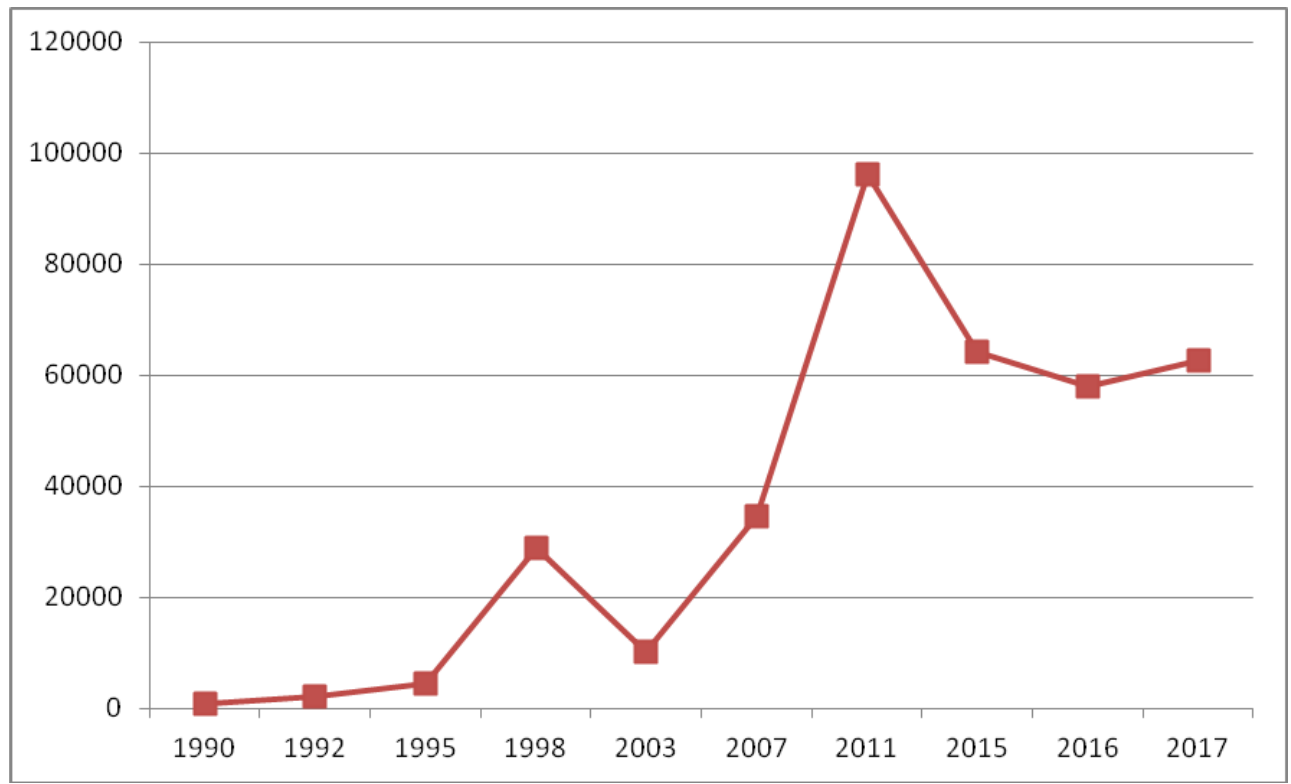

Elaboração: Maria Clara Leadebal Celestino, 2019. Fonte: UNCTAD.

Inicialmente é importante observar os anos selecionados, partindo da ideia que os governos políticos possuem estreita ligação com as medidas econômicas do país. De 1990 a 1992, durante o governo Collor, observa-se certa estabilidade, até mesmo estagnação, com subida suave de entrada de investimentos e proporcional descida de saída. De 1992 a 1995, com Itamar Franco, o quadro de estabilidade não é muito diferente, embora em ambos os sentidos de fluxo subam sutilmente. De 1995 a 1998, 
durante o primeiro governo de Fernando Henrique Cardoso, há uma subida considerável em relação aos outros dois governos nos dois sentidos de fluxo, chegando a cerca de 2800 milhões de dólares cada. Durante a década de 90, o Brasil se tornou um dos principais receptores de IED do mundo e, ainda assim, é uma proporção reduzida se comparada com os períodos futuros. Em seu segundo governo, até 2003, a entrada de investimentos cai quase pela metade, enquanto a queda de investimentos nacionais é tamanha que chega a ser pior do que a estagnação do início da década. Segundo Laplane (et al, 2000 apud SPOSITO, SANTOS, 2012), estas IED's se materializaram principalmente enquanto aquisições e fusões que contribuíram para a desnacionalização da economia, além de não terem resultado em aumento de exportações - havendo inclusive déficit da balança a partir de 1995, contrariando os anos anteriores - nem em formação de capital fixo relativo ao PIB.

De 2003 a 2007, no primeiro governo Lula, recupera-se a entrada de investimentos, com superação de U\$5729 milhões, e em relação a saída de investimentos tem-se uma guinada 28 vezes maior que seu estado no final do governo FHC. Até 2011, no segundo, segue-se a tendência de crescimento nos dois fluxos, atingindo os ápices tanto na saída com U\$3.091. 667,00 e de entrada com U\$64.291.000,00. Repare que mesmo em 2008 com a crise financeira, as recuperações de investimentos neutralizaram as perdas. De 2011 a 2015, durante o primeiro governo Dilma, tem-se quedas consideráveis nesses fluxos, mas até 2016, com seu segundo governo, esses investimentos caem, mas principalmente em proporção nos investimentos nacionais a ponto de ultrapassar o ponto inicial aqui abordado, indo realmente a valores negativos. Isto se deu por este governo ser permeado por crises políticas e econômicas que culminaram em um Impeachment dado em contexto de golpe jurídico-parlamentar e, portanto, perda de confiança por parte dos investidores, reverberando nesses fluxos. A partir do governo Temer, a começar ainda em 2016, os investimentos nacionais continuam na casa negativa, ainda que menos alarmantes, enquanto em relação à entrada, há um crescimento leve ainda que não alcance o estado anterior à crise. É visível assim que ao longo dos anos há mais oscilações que tendências a crescimento, o que também tende a ocorrer nos países periféricos no geral, segundo Sposito e Santos (2012).

21 Outra análise possível é a comparação gráfica dos valores desses fluxos nas regionalizações e países principais disponível no Gráfico 3. Nota-se que os valores dos fluxos da América Latina e Caribe como um todo sobem exponencialmente entre 2007 e 2014, obtendo queda entre 2015 e 2016, marcado pelas crises político-econômicas brasileiras, e retomada a partir de mesmo ano até 2017, segundo a Associação Latino Americana de Integração. A América do Sul é responsável pela maioria da destinação desses investimentos, destacando-se a Argentina. Além desta região, o destaque vai também para o México que durante todo este período ficou na casa dos 20.000 a 40.000 milhões de dólares. 
Gráfico 3 - Comparativo do Fluxo de Investimentos do Brasil na América Latina e Caribe entre 2007 e 2017 em Milhões de Dólares.

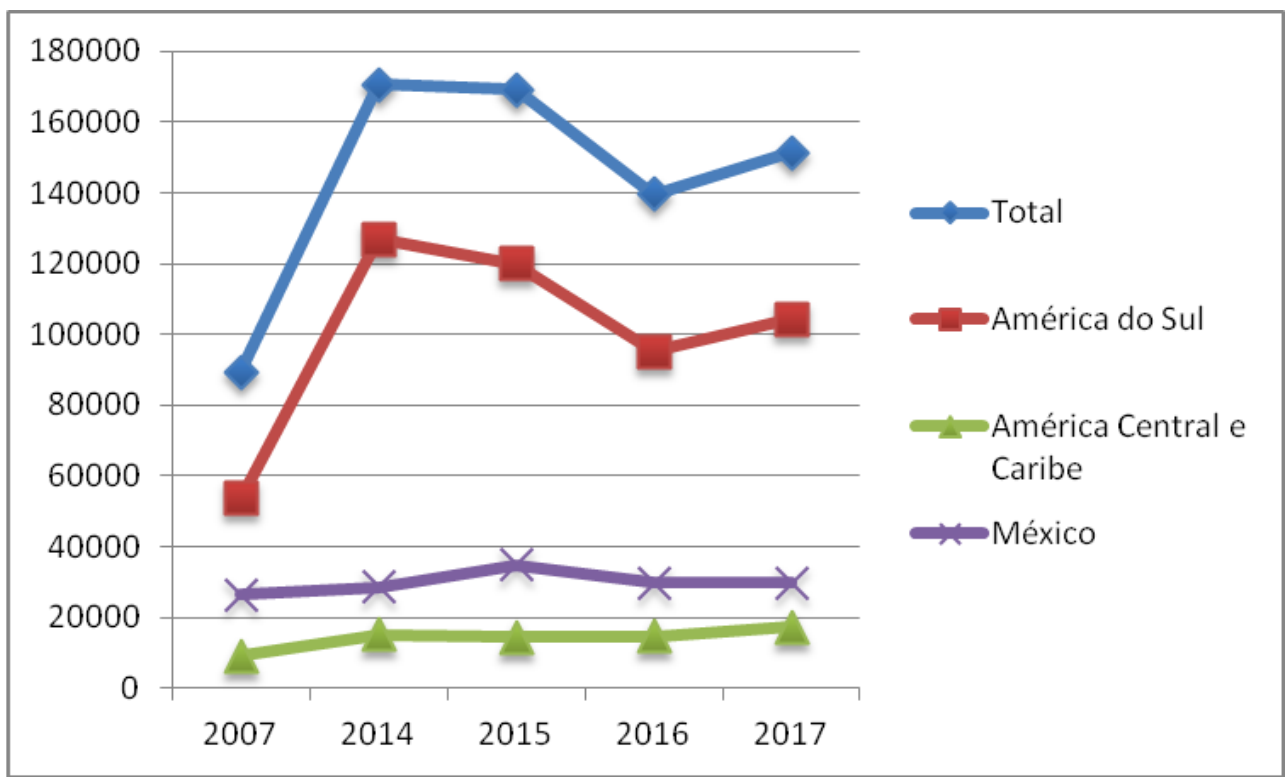

Organização: Maria Clara Leadebal Celestino, 2019. Fonte: World Investment Report 2018 - UNCTAD.

Neste sentido Zibechi (2012, p. 199) analisa que:

"Existe um consenso de que os investimentos brasileiros no exterior são ainda muito pequenos em relação ao PIB e podem crescer significativamente nos próximos anos. O Brasil foi e ainda é um dos grandes destinatários de IED (Investimento Estrangeiro Direto), mas na década de 1990 tornou-se um exportador de capitais (investimento brasileiro direto, ou IBD). Em alguns anos, o investimento brasileiro superou o investimento brasileiro no Brasil, no marco de uma profunda reacomodação mundial dos fluxos de capital, como conseqüência das crises das economias centrais e da crescente desarticulação geopolítica."

Apesar disso, este autor identifica que há pouca consistência na política brasileira de fomento nos investimentos no estrangeiro e sua relação com o desenvolvimento econômico do país.

Agora que já se abordou os quantitativos históricos dos investimentos do e no Brasil e as proporções de investimentos regionais, é interessante mostrar os destinos específicos dos investimentos em série histórica, a começar pela Figura1. 
Figura 1 - Mapa de Fluxos de IED do Brasil para os demais países da América Latina em 2007.

\section{Investimentos Estrangeiros Diretos do Brasil nos Demais Países da} América Latina [2007]

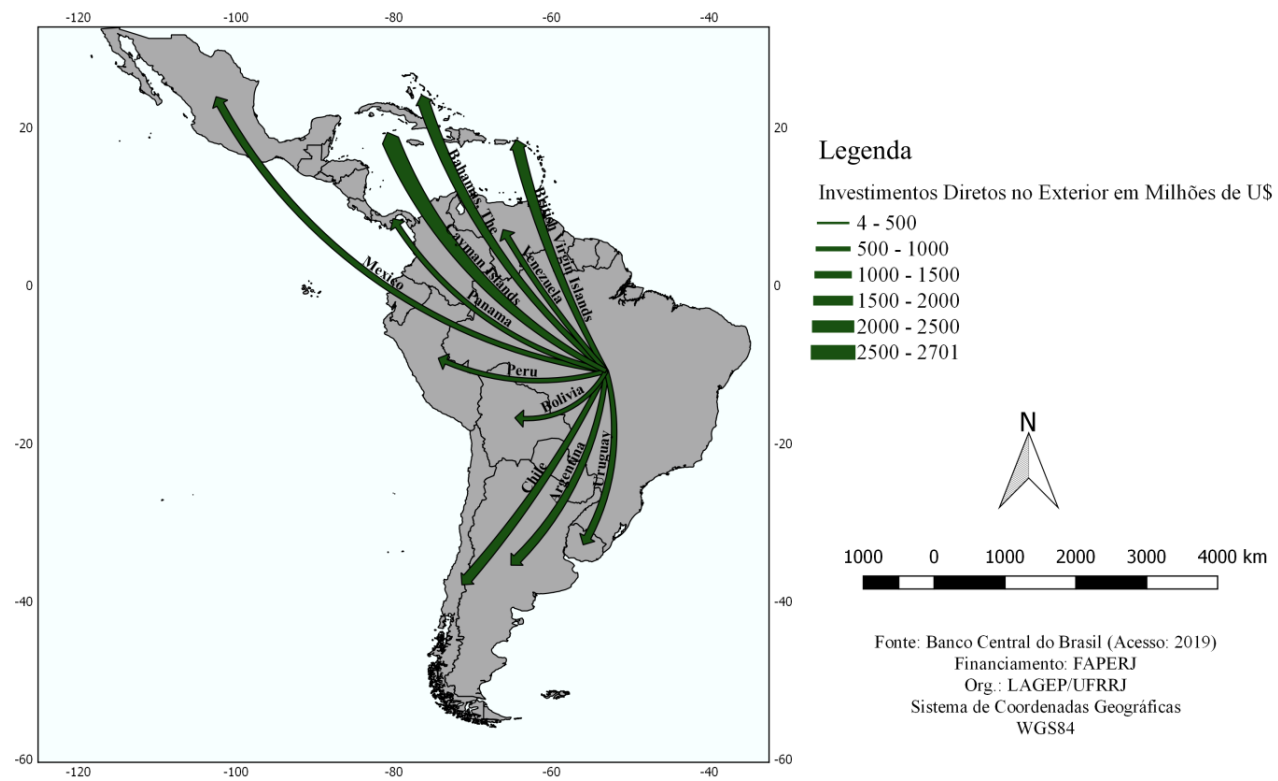

Elaboração: Maria Clara Leadebal Celestino, 2019. Fonte: Banco Central do Brasil.

Acima, é possível visualizar que as maiores quantias de IED são destinadas às Ilhas Cayman, Bahamas, às Ilhas Virgens Britânicas e ao Chile no ano de 2007 que corresponde ao início do segundo governo Lula. É importante ressaltar que esses dados foram os notificados pelo Banco Central do Brasil, podendo muitos investimentos não serem registrados pela mesma fonte, devido aos paraísos fiscais (SPOSITO, SANTOS, 2012). Inclusive, a notabilidade das Ilhas Cayman e das Bahamas em si mesmas já é algo intrigante à medida que demonstra a circularidade de investimentos e também a alta probabilidade de ser o país um paraíso fiscal em si mesmo devido ao grande sigilo bancário.

Os paraísos fiscais, também chamados de off-shorehavens, constituem territorialidades específicas cujos regulamentos internos do país se adequam funcionalmente ao sistema financeiro mundial, favorecendo sigilos e benefícios fiscais. Segundo Lia Osório Machado (1996, p.26), "sob a denominação genérica de "paraísos fiscais" existe uma variedade de serviços e formas de regulamentação a disposição de instituições e agentes bancários e financeiros que operam em escala global".

27 Assim, estes paraísos são posicionados em articulação com antigas metrópoles, e longitudinalmente de acordo com a praticidade dos horários de abertura e fechamento de mercados, uma vez que destas bases de operação, o dinheiro pode ser redirecionado para outros mercados financeiros.

Ainda de acordo com Lia Osório Machado (1996), um estudo do Fundo Monetário Internacional de 1991 concluiu que não-residentes de origem brasileira possuíam bilhões de dólares em depósitos em centros financeiros como as Ilhas Cayman, Ilhas Bahamans e Panamá. Entre 1991 e 1994, saíram do Brasil para Bahamas, Bermudas e Cayman 1,7 bilhões de dólares. Voltaram desses países quantias destinadas principalmente às bolsas de valores, reforçando a idéia de que apesar de serem 
registrados como saídas e entradas de investimentos estrangeiros diretos, os investimentos se materializam na valorização do próprio capital.

Figura 2 - Mapa de Fluxos de IED do Brasil para os demais países da América Latina em 2011

\section{Investimentos Estrangeiros Diretos do Brasil nos Demais Países da América Latina [2011]}

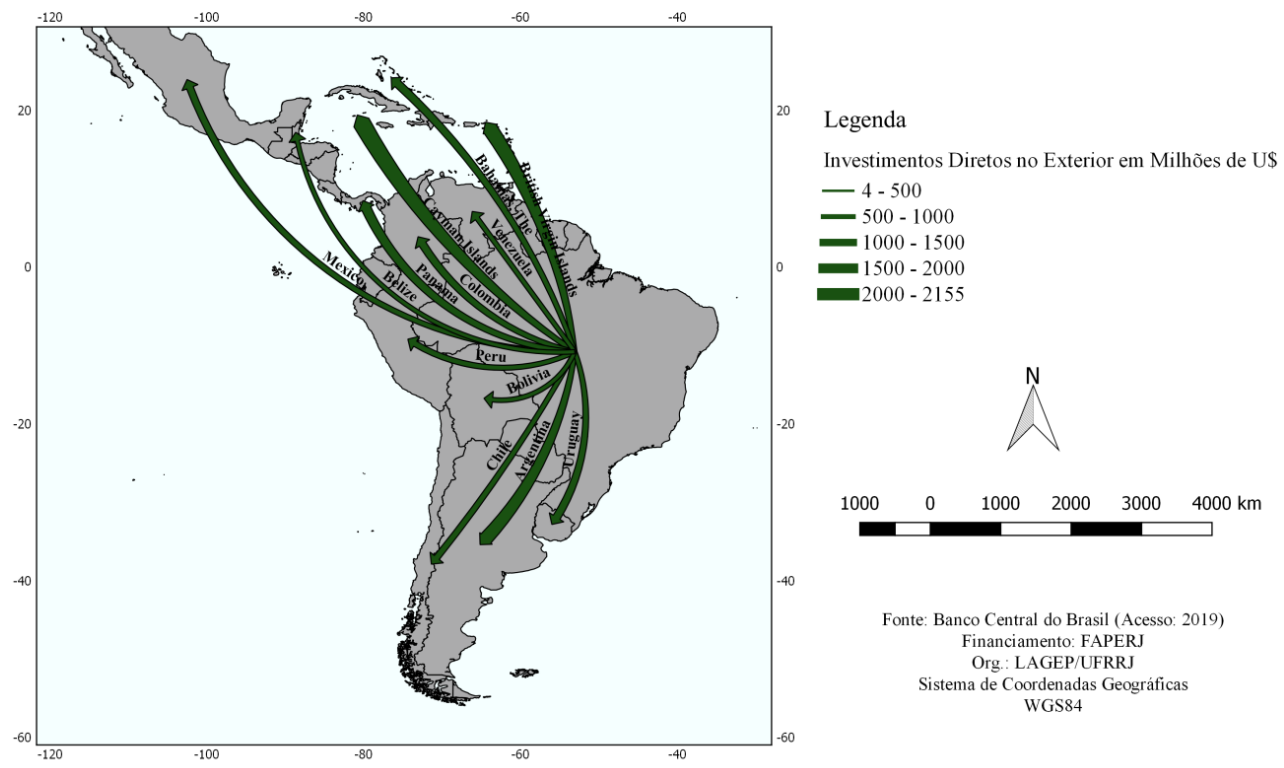

. Elaboração: Maria Clara Leadebal Celestino, 2019. Fonte: Banco Central do Brasil.

Já na Figura 2, com os dados de 2011 do início do Governo Dilma, mais uma vez se nota a predominância das Ilhas Cayman, com notabilidade também para as Ilhas Virgens Britânicas, e com a Argentina ganhando espaço. Além disso, Colômbia e Belize também se tornam novos destinos de investimentos. 
Figura 3 - Mapa de Fluxos de IED do Brasil para os demais países da América Latina em 2016.

\section{Investimentos Estrangeiros Diretos do Brasil nos Demais Países da América Latina [2016]}

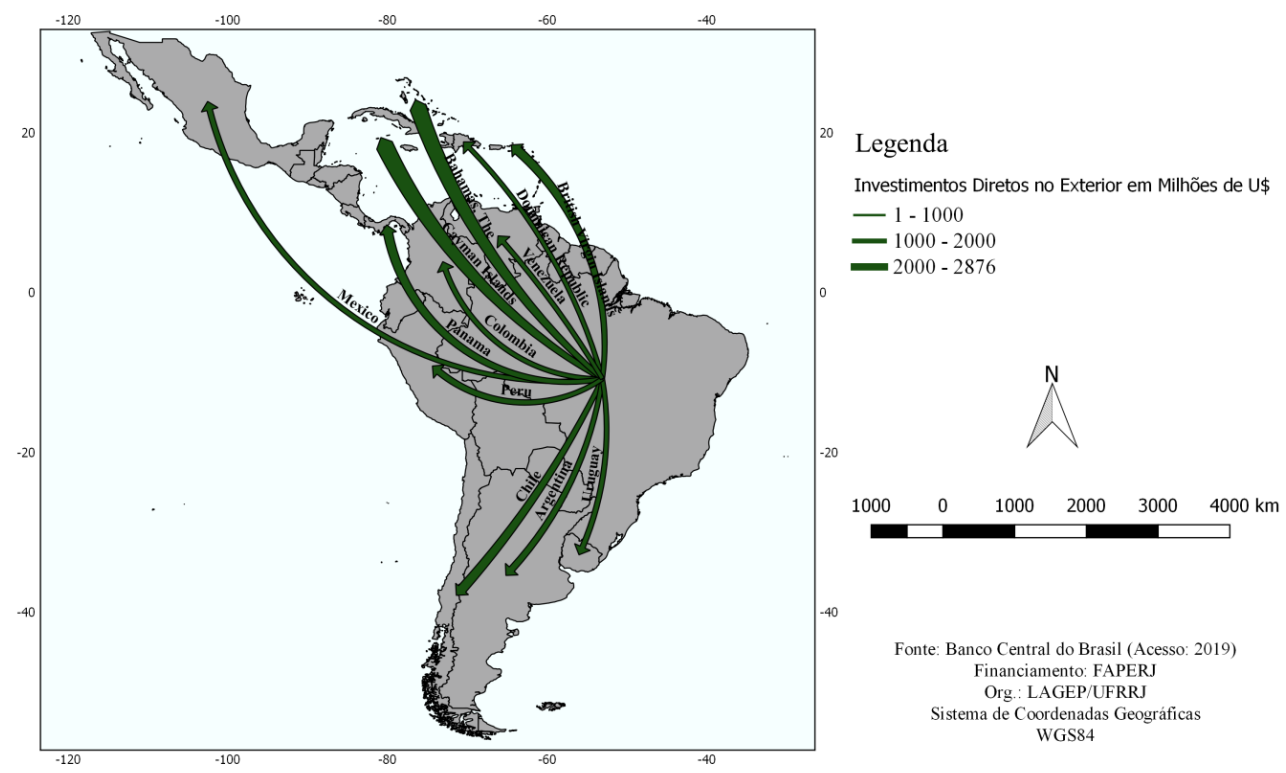

Elaboração: Maria Clara Leadebal Celestino, 2019. Fonte: Banco Central do Brasil.

Em 2016, com o início do governo Temer, vê-se na Figura 3 um retorno de crescimento para as Bahamas, com leve queda comparativa das Ilhas Virgens Britânicas e Argentina, mas manutenção da proporção das Ilhas Cayman.

Figura 4 - Mapeamento de Fluxos de IED do Brasil para os demais países da América Latina em 2018.

\section{Investimentos Estrangeiros Diretos do Brasil nos Demais Paises da} América Latina [2018]

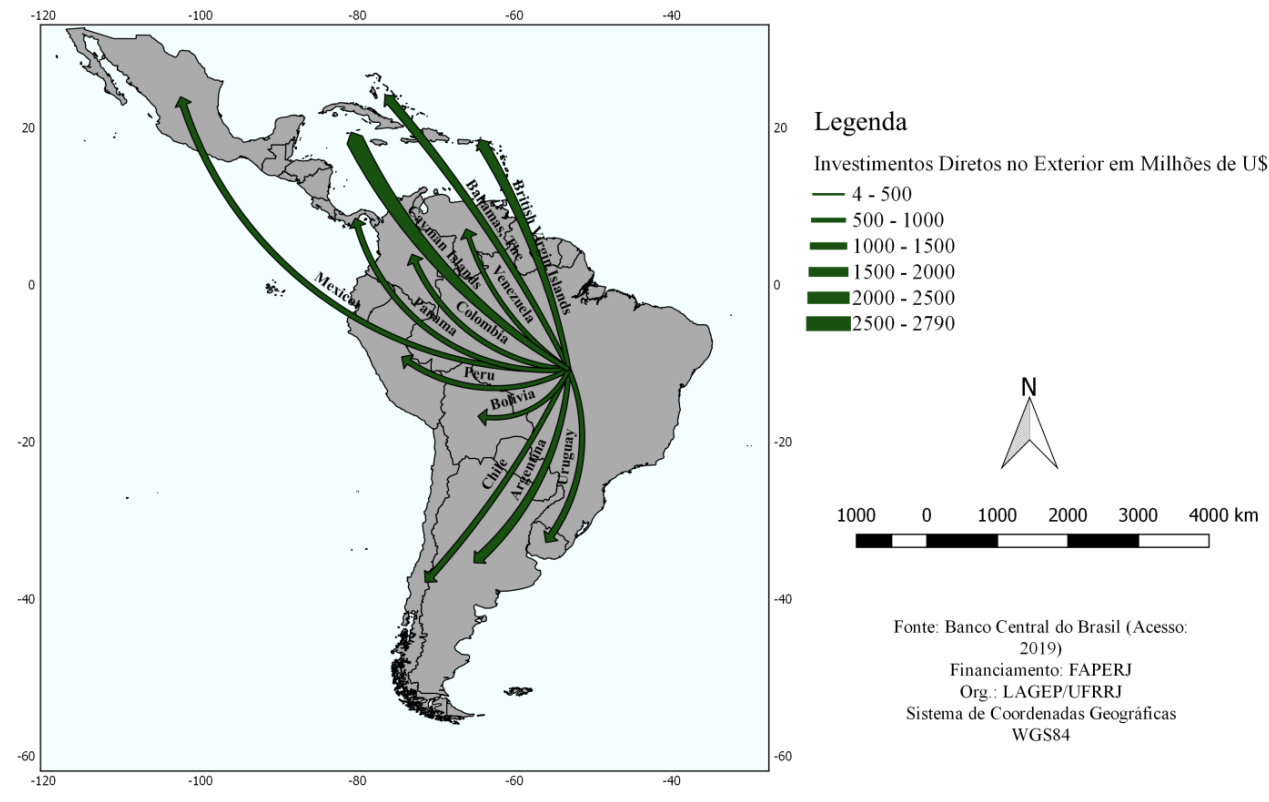

Elaborado por: Maria Clara Leadebal Celestino, 2019. Fonte: Banco Central do Brasil. 
, no mapa de 2018, com dados mais recentes do fim do Governo de Temer, da Figura 4, destacam-se os maiores investimentos nas Ilhas Cayman, Ilhas Virgens Britânicas e Argentina.

Algo a ser refletido é que os investimentos não são necessariamente territoriais no sentido material e social, mas são sempre territoriais em um contexto de relações de poder econômico. Isto ocorre porque o que é investido se dá, evidentemente, conforme os interesses do investidor que busca a valorização de seu próprio capital, fato que tende a se concretizar mais sob a forma de ativos financeiros do que sob a forma de projetos materiais.

Vê-se que através dos anos, a prioridade dos investimentos se encontra nas Ilhas Cayman, Ilhas Virgens Britânicas e nas Bahamas, destinando-se poucas vezes em maior quantidade para países vizinhos e parceiros em termos de cooperação, como a Argentina, o Chile e o Uruguai, por exemplo. Sabendo das facilidades de sigilo e menores taxações dessas ilhas e da proporção monetária que pôde ser calculada pelo Banco Central do Brasil, percebe-se que os investimentos certamente permanecem rendendo capital financeiro para os investidores e não necessariamente para os países a que são destinados. A partir disto, é possível perceber que boa parte dos investimentos não tem grande papel na integração regional ou, se quer, na Cooperação Sul-Sul.

\section{Resultados econômicos dos IED nos países da América Latina}

Segundo Dunning (1981 apud SPOSITO, SANTOS, 2012), é possível dividir os países em quatro grupos no que se refere à PIB per capita e entrada e saída de IED: nenhuma saída de IED; Países com PIB per capita entre U $\$ 2000$ e U $\$ 4750$, onde a diferença entre entrada e saída de IED é cada vez menor; estrangeiro. 


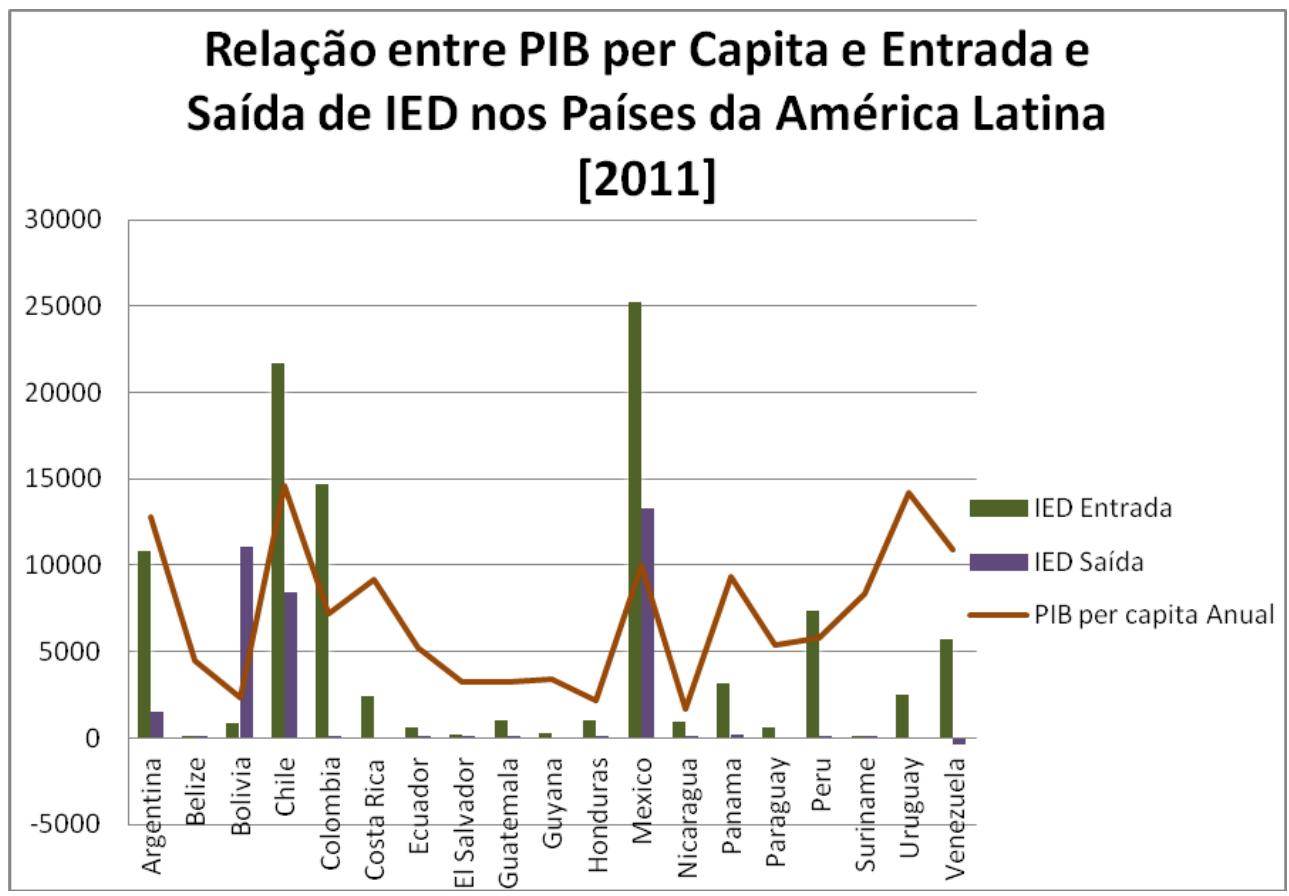

Elaboração: Maria Clara Leadebal Celestino, 2019. Fonte: Cepalstat; UNCTAD.

Para uma análise aprofundada do gráfico, justifiquemos inicialmente a escolha do ano de 2011 por possuir mais dados disponibilizados pelos países. Observa-se que Argentina, Chile e Uruguai se destacam em PIB per capita, além de Chile e México demonstrarem os maiores níveis de entrada e saída de IED.

Outro parâmetro a ser avaliado é que o PIB per capita disponibilizado pelo Cepalstat é dado anualmente enquanto o referido por Dunning é mensal. Neste sentido, fazendo as devidas divisões, têm-se que até U\$400 mensais estão Belize, Bolívia, El Salvador, Guatemala, Guyana, Honduras e Nicarágua, que no gráfico, de fato, correspondem aos com poucas entradas e saídas de IED, com exceção da Bolívia que possui alta saída. Todos os outros países se encontram entre a faixa de U\$ 400 e U\$ 1500 mensais, correspondendo novamente às expectativas de Dunning, ainda que os países que se destaquem estejam em crescimento exponencial de IED há mais tempo. Desta forma, vê-se que os países com maiores PIB per capita se enquadram no segundo grupo da classificação de Dunning. Assim vê-se que em muito se aplica a teoria de Dunning nas correlações de PIB per capita e IED, ainda que em termos de América Latina seja difícil associar o PIB per capita à distribuição de riquezas à medida que há uma minoria com mais posses que desequilibra esta distribuição.

Pode-se ainda dividir os investimentos estrangeiros diretos em estágios de desenvolvimento a partir de suas características, ainda de acordo com este autor. Em uma primeira onda, as IED são regionais, procurando recursos e mercados nos países em desenvolvimento. Na segunda, estão em expansão para o global, mas ainda majoritariamente regionais, procurando recursos e mercados em países em desenvolvimento e ativos e mercados nos industriais. Enquanto na terceira onda, há uma base global de procura de eficiência e uso otimizado de cada vantagem comparativa e competitiva dos países. O Brasil se insere nesta segunda onda, com 
empresas multinacionais que atuam principalmente em seu entorno estratégico, mas que também começam a investir em países centrais, complexificando as suas relações.

Isto evidencia que apesar dessas empresas investidoras serem multinacionais, sua estratégia nem sempre é global, uma vez que podem ser aplicadas em setores e segmentos que não apresentam demandas expressivas globais, podendo seus lucros serem mais significativos em eixos regionais. Mesmo as empresas globais acabam por concentrar suas atividades em uma determinada atividade, resistindo as diferenças econômicas entre países. Inclusive, apesar de inicialmente haver uma diferença conceitual entre empresas multinacionais, globais e internacionais - a primeira com presença loca forte por receptividade de diferenças nacionais, a segunda com obtenção de vantagens de custo por meio de operações centralizadas em escala global e a terceira com exploração de conhecimento e recursos da matriz somada à difusão e adaptação mundial -, com o avanço da globalização essas características começaram a se misturar uma vez que essas empresas precisavam desenvolver a competitividade global, flexibilidade multinacional e capacidade de aprendizagem internacional (BARTLETT; GHOSHAL, 1992 apud SPOSITO; SANTOS, 2012).

\section{Considerações finais}

A partir do que foi apresentado é possível concluir que os Investimentos Estrangeiros Diretos têm assumido papel de grande relevância em termos de Cooperação Econômica e de fator de interdependência na Economia Mundo. No entanto, é preciso considerar seu fator coercitivo à medida que atribui a investidores e empresas um poder econômico internacional que acaba muitas vezes por reproduzir relações hierárquicas e perversas que deixam a cooperação apenas na esfera do discurso entre países.

A dificuldade da classificação de dados e, consequentemente, sua coleta foram considerados e, ainda assim, foi identificada os sobressalentes investimentos do Brasil para ilhas consideradas paraísos fiscais ao invés de seus países vizinhos com os quais estabelece acordos de cooperação. Isto traz à tona a prevalência da valorização do capital em detrimento do investimento voltado para o desenvolvimento territorial.

Assim, evidencia-se que o Brasil tem assumido uma posição de complexidade com seus investimentos na América Latina, o que contribui para sua projeção regional. No entanto, isto não redime o país de forma alguma, uma vez que a Cooperação Econômica como está instituída se resume à consideração prioritária e crua da cooperação pelo dinheiro.

BIBLIOGRAFIA

AMAL, Mohamed; SEABRA, Fernando. Determinantes do Investimento Direto Externo (IDE) na América Latina: Uma Perspectiva Institucional. Revista Economia, v.8, n.2. Brasília, 2007.

BRASIL. Banco Central do Brasil: Série Histórica dos Fluxos de Balanço de Pagamentos Distribuições por País ou Por Setor. Brasília, 2018. Disponível em: https://www.bcb.gov.br/ 
acessoinformacao/legado?url=https:

\%2F\%2Fwww.bcb.gov.br\%2Fhtms\%2FInfecon\%2FSeriehistBalanco.asp\%3Fidpai\%3Dseriespex.

Acesso em: 8 de mai. 2019.

CHESNAIS, François. A Mundialização do Capital. São Paulo: Editora Xamã, $1^{\mathfrak{a}}$ ed, 1996.

CHESNAIS, François. Mundialização: O Capital Financeiro no Comando. Revista Outubro, ed. 5, 2001. p. 7-28.

DUNNING, John H. Explaining the International Direct Investment Position of Countries: Towards a Dynamic or Developmental Appoach. In: BLACK, J.; DUNNING, J.H. International Capital Movements: Papers of the Fifth Annual Conference of the International Economics Study Group. London: Macmillan, $1^{\mathrm{a}}$ ed., 1982. P. 84 - 121.

HARVEY, David. A Produção Capitalista do Espaço. São Paulo: Annablume, $2^{\mathrm{a}}$ ed, 2006 [2001].

MACHADO, Lia Osório. O Comércio Ilícito de Drogas e a Geografia da Integração Financeira: Uma Simbiose? In: CASTRO et al (eds.) Brasil: Questões Atuais da Reorganização do Território. Rio de Janeiro, Bertrand Brasil, 1996.

MORASSO, Carla. La Cooperación Sur-Sur entre Argentina y África Sub-Sahariana: el caso de la agricultura. Revista Neiba, ano II, n 2. Novembro de 2013.

SPOSITO, Eliseu Savério. SANTOS, Leandro Bruno. O Capitalismo Industrial e as Multinacionais Brasileiras. Outras Expressões, $1^{\mathrm{a}}$ Ed. São Paulo, 2012.

UNCTAD. United Nations Conference on Trade and Development Stat: Data Center. Disponível em: https://unctadstat.unctad.org/wds/ReportFolders/reportFolders.aspx. Acesso em: 7 de Maio de 2018.

ZIBECHI, Raul. Brasil Potência: Entre a Integração Regional e um Novo Imperialismo. Rio de Janeiro: Consequência, $2^{\mathrm{a}} \mathrm{ed}, 2012.333$ p.

\section{RESUMOS}

O presente texto busca compreender as relações de Cooperação Sul-Sul em meio às complexidades geopolíticas e geoeconômicas do sistema mundial, a partir da interpretação do Brasil e sua projeção regional na América Latina, tendo esses investimentos como vetores de desenvolvimento econômico. Tomamos como fontes de pesquisa os dados do Banco Central do Brasil e UNCTAD que foram sistematizados e organizados para confecção de cartografias dessa cooperação. Como resultados, apresentamos o mapeamento dos Investimentos Estrangeiros Diretos, tecendo a evolução histórica de seus fluxos, que servem enquanto estratégias que se alicerçam na conjuntura e estrutura do Capitalismo Financeiro mundial.

This text aims the comprehension of South-South Cooperation relations among the geopolitical and geoeconomics complexities of the world system, as from the interpretation of Brazil and its regional projection on Latin America, having these investments as economic development vectors. We take as research sources the data from BANCO CENTRAL DO BRASIL and UNCTAD wich were systematized and organized for the cooperation cartographies production. As results the Foreign Direct Investment's mapping were presented, weaving the historical evolution of its fluxes, which ones serve as strategies that ground in the conjuncture and structure of the worldwide Financial Capitalism.

Este texto trata de La comprensión de las relaciones de La Cooperación Sur-Sur en medio de las complexidades geopolíticas y geoeconómicas en el sistema mundial, desde la interpretación del 
Brasil y su proyección regional en América Latina, tiendo estos investimentos como vectores de desenvolvimiento económico. Tomamos como fuentes de pesquisa los daos del BANCO CENTRAL DO BRASIL y UNCTAD que fueran sistematizados y organizados para confección de cartografías de esta cooperación. Como resultados, presentamos el mapeo de las Inversiones Extranjeras Directas, tejiendo la evolución histórica de sus flujos, que sirven como estrategias que se cimientan en la coyuntura y estructura del Capitalismo Financiero mundial.

Ce document a pour objectif de comprendre les relations de Coopération Sud-Sud au sein des complexités géopolitiques et géoéconomiques du système mondial, en se basant sur l'interprétation du Brésil et de sa projection régionale en Amérique Latine, ces investissements étant des vecteurs du développement économique. Nous avons pris comme source de recherche les données de la BANCO CENTRAL DO BRASIL et UNCTAD, systématisées et organisées pour réaliser des cartographies de cette coopération. En conséquence, nous présentons la cartographie de l'Investissement Direct Étranger, qui tisse l'évolution historique de ses flux, qui servent de stratégies fondées sur la conjoncture et la structure du Capitalisme Financier mondial.

\section{ÍNDICE}

Palavras-chave: Investimentos Estrangeiros Diretos, Cooperação Econômica, América Latina. Palabras claves: Inversiones Extranjeras Directas, Cooperación Económica, América Latina. Keywords: Foreign Direct Investment, Economic Cooperation, Latin America.

Mots-clés: Investissement Direct Étranger, Coopération Économique, Amérique Latine.

\section{AUTOR}

\section{MARIA CLARA LEADEBAL CELESTINO}

Graduanda em Geografia -

Universidade Federal Rural do Rio de Janeiro

Bolsista de Iniciação Científica - FAPERJ 